\title{
PENGARUH MEDIA DAN INTENSITAS NAUNGAN TERHADAP PERTUMBUHAN BIBIT TANCANG (Bruguiera gymnorrhiza (L.) Lamk.)
}

\author{
Effects of Growing Media and Shade Level on the Growth of Tancang Seedling \\ (Bruguiera gymnorrhiza (L.) Lamk.) \\ Cecep Kusmana $^{1 *}$ dan Yolan Yussy Sukaesih ${ }^{1}$
}

(Diterima September 2020/Disetujui Desember 2020)

\begin{abstract}
Bruguiera gymnorrhiza is a mangrove species that can be used to rehabilitate mangrove forest. The information about the response of mangrove seedlings to the factors that affect its growth is needed to ensure its survival rate. This study aimed to examine the response of Bruguiera gymnorrhiza seedlings to the factors that affect its growth such as media and shade level. This research used a Completely Randomized Factorial Design (CRFD) with the treatments of growing media (A) and shade level $(N)$ of 3 levels on each factor, that are mud (A0); mud and compost (A1); and mud, compost, sand (A2); also 0\% shade (NO); 50\% shade (N1); and 70\% shade (N2) on the 3 months old seedlings. The results showed that the treatment of shade level significantly affected the growth response of B. gymnorrhiza seedlings, while the treatment of growing media and interaction of both treatments did not show a significant response. The $0 \%$ shade level gave the best growth response of $B$. gymnorrhiza seedlings.
\end{abstract}

Keywords: Growth rate, light level, mangrove, rehabilitation, seedbed

\section{PENDAHULUAN}

Hutan mangrove merupakan formasi dari tumbuhan tertentu yang umumnya tumbuh dan berkembang di kawasan pesisir di daerah tropika dan subtropika. Indonesia memiliki hutan mangrove terluas dari wilayah mangrove di dunia. Hutan mangrove memiliki berbagai manfaat pada aspek ekologi, ekonomi, dan sosial. Mangrove berfungsi menjaga pesisir pantai dan muara sungai dari abrasi serta sebagai habitat biota untuk mencari makan dan berkembang biak. Secara tradisional, mangrove di Indonesia dimanfaatkan untuk kebutuhan sehari-hari seperti kayu bakar, arang, tannin, bahan pangan, dan obat-obatan (Kusmana 2008).

Keberadaan mangrove mulai mengalami banyak gangguan akibat aktivitas manusia maupun fenomena alam terutama perubahan iklim akibat pemanasan global (Duke et al. 2010). Melihat besarnya kerusakan yang terjadi di hutan mangrove, upaya rehabilitasi mangrove telah banyak dilakukan namun tidak sedikit yang gagal. Dalam beberapa situasi seperti tanah penanaman yang terlalu keras atau terlalu lembek dan kondisi lapang yang ombaknya terlalu besar, penanaman dengan persemaian dibutuhkan untuk meningkatkan peluang keberhasilan tumbuh suatu tanaman (Kusmana et al. 2008). Sehingga diperlukan informasi mengenai faktor yang sesuai terhadap pertumbuhan jenis magrove. Salah satu faktor

\footnotetext{
${ }^{1}$ Departemen Silvikultur, Fakultas Kehutanan dan Lingkungan, Institut Pertanian Bogor

* Penulis korespondensi:

e-mail: ckmangrove@gmail.com
}

tersebut adalah pengaruh media tanam dan intensitas naungan.

Tancang (Bruguiera gymnorrhiza) merupakan salah satu spesies penting pada ekosistem hutan mangrove. Jenis ini menempati habitat bagian tengah sampai tepi mangrove, sepanjang tanggul tambak, dan di pinggir sungai kecil (Kusmana et al. 2008). Salah satu upaya dalam menjaga keseimbangan ekosistem hutan mangrove adalah dengan melakukan budidaya jenis mangrove melalui perlakuan yang tepat. Penelitian ini bertujuan mengidentifikasi respon pertumbuhan bibit $B$. gymnorrhiza terhadap pengaruh media dan intensitas naungan.

\section{METODE PENELITIAN}

\section{Waktu dan Lokasi Penelitian}

Penelitian dilaksanakan pada bulan Januari sampai bulan April 2020 di rumah kaca Laboratorium Ekologi Hutan Departemen Silvikultur Fakultas Kehutanan IPB. Sampel bibit B. gymnorrhiza berumur 3 bulan, berasal dari Elang Laut, Jakarta Utara.

\section{Alat dan Bahan}

Alat yang digunakan dalam penelitian antara lain alat tulis, digital caliper, penggaris, timbangan digital, oven, dan kamera. Adapun bahan yang digunakan yaitu, media bibit (lumpur, pasir, dan kompos), paranet dengan intensitas naungan $50 \%$ dan $70 \%$, polybag berukuran 10 $\mathrm{cm}$ x $20 \mathrm{~cm}$, kolam terpal, ajir, serta bibit B. gymnorrhiza sebanyak 36 bibit. 


\section{Prosedur Penelitian}

Penelitian ini menggunakan rancangan percobaan RAL faktorial. Terdapat dua faktor yang diuji yaitu faktor media (A) dan faktor intensitas naungan $(\mathrm{N})$ sebanyak 3 taraf pada masing-masing faktor. Taraf pada faktor media yaitu lumpur (A0), lumpur dan kompos (7:3) (A1), dan lumpur, kompos, pasir (4:3:3) (A2). Taraf pada faktor intensitas naungan yaitu naungan $0 \%(\mathrm{~N} 0)$, naungan $50 \%(\mathrm{~N} 1)$, dan naungan $70 \%(\mathrm{~N} 2)$, sehingga terdapat 9 kombinasi perlakuan sebagai berikut:

A0N0 : media lumpur + intensitas naungan $0 \%$

A0N1 : media lumpur + intensitas naungan $50 \%$

A0N2 : media lumpur + intensitas naungan $70 \%$

A1N0 : media lumpur dan kompos + intensitas naungan $0 \%$

A1N1 : media lumpur dan kompos + intensitas naungan $50 \%$

A1N2 : media lumpur dan kompos + intensitas naungan $70 \%$

A2N0 : media lumpur, kompos, dan pasir + intensitas naungan $0 \%$

A2N1 : media lumpur, kompos, dan pasir + intensitas naungan $50 \%$

A2N2 : media lumpur, kompos, dan pasir + intensitas naungan $70 \%$

\section{Pemilihan dan pengangkuan bibit}

Bibit B. gymnorrhiza yang berasal dari Elang Laut, Jakarta Utara dipilih sebanyak 36 bibit berdasarkan kenampakan yang sehat dengan tinggi dan jumlah daun yang relatif sama. Bibit tersebut kemudian diangkut ke lokasi penelitian di rumah kaca Laboratorium Ekologi Hutan, Departemen Silvikultur, Fakultas Kehutanan, Institut Pertanian Bogor.

\section{Persiapan media dan penanaman}

Perlakuan media yang digunakan yaitu (1) lumpur, (2) lumpur dan kompos (7:3), dan (3) lumpur, kompos, pasir (4:3:3). Media disiapkan ke dalam polybag berukuran $10 \mathrm{~cm}$ x $20 \mathrm{~cm}$. Bibit B. gymnorrhiza kemudian dipindahkan dari wadah pengangkutan ke dalam media yang telah disiapkan pada polybag dan diletakkan pada kolam dengan naungan berbeda. Kolam penelitian terbuat dari terpal berukuran $3.5 \mathrm{~m} \times 1 \mathrm{~m} \times 0.3 \mathrm{~m}$ dengan genangan air tawar setinggi permukaan tanah pada polybag.

\section{Pengukuran bibit}

Pengukuran dilakukan satu kali seminggu selama 12 minggu setelah waktu aklimatisasi. Parameter yang diamati dalam penelitian adalah sebagai berikut:

\section{Tinggi bibit}

Tinggi bibit diukur $1 \mathrm{~cm}$ diatas propagul hingga titik tumbuh pucuk bibit menggunakan mistar.

\section{Diameter batang}

Diameter batang diukur pada batang yang telah ditandai $1 \mathrm{~cm}$ diatas propagul bibit menggunakan digital caliper.

\section{Jumlah daun}

Jumlah daun dihitung dan diamati pada seluruh helai bibit.

\section{Berat basah total}

Berat basah total diukur menggunakan timbangan digital pada akhir pengamatan. Bibit dipisahkan bagian akar dan pucuknya kemudian dijumlahkan masing-masing berat basah pucuk dan berat basah akar.

\section{Berat kering total}

Berat kering total diukur setelah bagian pucuk dan bagian akar tanaman dikeringkan menggunakan oven pada suhu $80^{\circ} \mathrm{C}$ dalam waktu 48 jam (Permatasari dan Kusmana 2011). Masing-masing bagian ditimbang menggunakan timbangan digital dan dijumlahkan untuk memperoleh berat kering totalnya.

\section{Nisbah pucuk akar}

Nisbah pucuk akar (NPA) dihitung dengan membandingkan berat kering pucuk dan berat kering akar tanaman. Berikut rumus untuk menghitung NPA:

$$
N P A=\frac{\text { Berat kering pucuk }(g)}{\text { Berat kering akar }(g)}
$$

\section{Pengolahan dan analisis data}

Hasil data yang diperoleh diolah secara deskriptif menggunakan aplikasi Microsoft Office Excel 2010. Selanjutnya data dianalisis menggunakan analisis ragam pada aplikasi Statistical Analysis System (SAS) 9.0.1 untuk mengetahui pengaruh media, intensitas naungan, dan interaksi keduanya serta dilakukan uji lanjut menggunakan uji Duncan pada taraf $5 \%(\alpha=0.05)$. Media kontrol (lumpur) diuji analisis di EBL-ICBB untuk mengetahui tekstur fraksi tanah.

\section{HASIL DAN PEMBAHASAN}

Pertumbuhan tanaman merupakan perubahan yang bersifat tak terbalikkan (irreversible). Pada penelitian ini, dilakukan pengujian pertumbuhan bibit B. gymnorrhiza terhadap pengaruh intensitas naungan dan media tanam. Pertumbuhan bibit B. gymnorrhiza diukur dari parameter tinggi, diameter, jumlah daun, berat basah, berat kering, dan nisbah pucuk akar.

\section{Respon Pertumbuhan Bibit}

Bibit tancang (B. gymnorrhiza) menunjukkan respon yang berbeda terhadap pemberian perlakuan media dan

Tabel 1 Rekapitulasi hasil sidik ragam pengaruh perlakuan terhadap variabel pertumbuhan bibit B. gymnorrhizza

\begin{tabular}{lccc}
\hline \multicolumn{1}{c}{ Parameter } & \multicolumn{3}{c}{ F hitung } \\
\cline { 2 - 4 } & A & N & AN \\
\hline Tinggi & tn & $*$ & tn \\
Diameter & tn & $*$ & tn \\
Jumlah daun & tn & $*$ & tn \\
Berat basah total & tn & $*$ & tn \\
Berat kering total & tn & tn & tn \\
Nisbah pucuk akar & tn & $*$ & tn \\
\hline
\end{tabular}

Keterangan:

$*$ = berpengaruh nyata pada selang kepercayan 95\%;

tn = tidak berpengaruh nyata 
intensitas naungan yang diuji. Berdasarkan hasil sidik ragam yang disajikan pada Tabel 1 diketahui bahwa intensitas naungan memberikan pengaruh yang berbeda nyata terhadap variabel pertumbuhan bibit $B$. gymnorrhiza. Media tanam dan interaksi antara media dan intensitas naungan tidak memberikan respon pertumbuhan yang berbeda nyata. Variabel pertumbuhan yang dipengaruhi oleh perlakuan intensitas naungan antara lain pertumbuhan tinggi, diameter batang, jumlah daun, berat basah, serta nisbah pucuk akar bibit $B$. gymnorrhiza.

\section{Pertumbuhan Tinggi}

Perlakuan intensitas naungan memberikan pengaruh yang berbeda terhadap pertumbuhan tinggi bibit $B$. gymnorrhiza sehingga dilakukan uji lanjut pada Tabel 2. Intensitas naungan 0\% (N0) memberikan hasil rata-rata pertumbuhan yang paling baik $(13.33 \mathrm{~cm})$ dibandingkan dengan naungan 50\% (N1) dan naungan 70\% (N2).

Pertambahan tinggi tanaman disebabkan oleh aktivitas pembelahan sel meristem apikal. Proses pembelahan sel tersebut membutuhkan karbohidrat dari proses fotosintesis untuk penambahan tinggi (Hastuti et al. 2016). Pertambahan tinggi tanaman ini diawali dengan bertambahnya pucuk yang semakin panjang kemudian dilanjutkan dengan perkembangannya menjadi batang dan daun.

Tinggi B. gymnorrhiza salah satunya dipengaruhi oleh pengaruh intensitas naungan. Naungan akan mempengaruhi jumlah intensitas cahaya matahari yang mengenai tanaman. Tabel 2 menunjukkan bahwa $B$. gymnorrhiza cocok tumbuh pada intensitas naungan $0 \%$. Hal ini sejalan dengan Mangora et al. (2017) bahwa $B$. gymnorrhiza memiliki pertumbuhan tinggi, diameter, serta persentase keberhasilan hidup yang lebih tinggi pada naungan terbuka. Hal ini juga sejalan dengan penelitian Jiang et al. (2019) yang melakukan uji pertumbuhan lima jenis mangrove (Aegiceras corniculatum, Avicennia marina, Bruguiera gymnorrhiza, Kandelia obovata, dan Rhizophora stylosa) pada berbagai pengaruh elevasi intertidal dan tingkatan

Tabel 2 Hasil uji Duncan pengaruh intensitas naungan terhadap pertumbuhan tinggi bibit

\begin{tabular}{lc}
\hline Intensitas naungan & $\begin{array}{c}\text { Rata-rata pertumbuhan } \\
\text { tinggi bibit }(\mathrm{cm})\end{array}$ \\
\hline N0 $(0 \%)$ & $13.33 \mathrm{a}$ \\
N1 $(50 \%)$ & $9.88 \mathrm{~b}$ \\
N2 $(70 \%)$ & $5.96 \mathrm{c}$ \\
\hline
\end{tabular}

Nilai dengan huruf yang berbeda menunjukkan perbedaan nyata pada selang kepercayaan $95 \%$

Tabel 3 Hasil uji Duncan pengaruh intensitas naungan terhadap pertumbuhan diameter bibit

\begin{tabular}{lc}
\hline \multicolumn{1}{c}{ Intesitas naungan } & $\begin{array}{c}\text { Rata-rata pertumbuhan } \\
\text { diameter bibit }(\mathrm{cm})\end{array}$ \\
\hline N0 $(0 \%)$ & $0.233 \mathrm{a}$ \\
N1 $(50 \%)$ & $0.095 \mathrm{~b}$ \\
N2 $(70 \%)$ & $0.041 \mathrm{c}$ \\
\hline
\end{tabular}

Nilai dengan huruf yang berbeda menunjukkan perbedaan nyata pada selang kepercayaan $95 \%$ cahaya. Hasil penelitian tersebut menunjukkan bahwa bibit B. gymnorrhiza memiliki rata-rata tingkat kelangsungan hidup yang paling tinggi dibandingkan dengan jenis lainnya, namun menurun seiring dengan kenaikan intensitas naungannya. Allen dan Duke (2008) menyatakan bahwa $B$. gymnorrhiza merupakan salah satu jenis mangrove yang memiliki sifat toleransi tinggi. Jenis ini mampu tumbuh pada naungan dan tumbuh baik pada cahaya penuh.

\section{Diameter}

Hasil uji Duncan menunjukkan bahwa terdapat pengaruh yang berbeda antara ketiga perlakuan dengan respon pertumbuhan diameter bibit. Hasil terbaik ditunjukkan oleh pengaruh intensitas naungan $0 \%$ (N0) $(0.233 \mathrm{~cm})$. Naungan cahaya yang semakin rendah akan meningkatkan pertumbuhan diameter batang tanaman. Pertumbuhan diameter erat kaitannya dengan laju fotosintesis. Suci dan Heddy (2018) mengemukakan bahwa pertumbuhan diameter yang terhambat dapat disebabkan oleh produk fotosintesis serta spektrum cahaya matahari yang kurang merangsang aktivitas hormon dalam pembentukan sel meristematik ke arah diameter batang, terutama pada intensitas cahaya yang rendah. Oleh karena itu perlakuan tanpa naungan memungkinkan cahaya matahari yang masuk menjadi optimum untuk pertumbuhan bibit mangrove.

\section{Jumlah Daun}

Perlakuan intensitas naungan berpengaruh nyata terhadap pertumbuhan jumlah daun bibit $B$. gymnorrhiza . Berdasarkan Tabel 4 menyatakan bahwa jumlah daun meningkat sebesar 11.17 helai pada naungan $0 \%$ (N0). Bibit yang diletakkan pada perlakuan tanpa naungan menghasilkan jumlah daun yang lebih besar daripada naungan $50 \%$ (N1) dan $70 \%$ (N2). Daun memiliki peranan penting dalam kehidupan tumbuhan. Daun memiliki fungsi utama sebagai tempat proses fotosintesis serta berperan sebagai alat transpirasi dan respirasi. Pertumbuhan daun berbanding lurus dengan

Tabel 4 Hasil uji Duncan pengaruh intensitas naungan terhadap pertumbuhan jumlah daun bibit B. gymnorrhiza

\begin{tabular}{lc}
\hline \multicolumn{1}{c}{ Intensitas naungan } & Rata-rata jumlah daun \\
\hline N0 $(0 \%)$ & $11.17 \mathrm{a}$ \\
N1 $(50 \%)$ & $6.00 \mathrm{~b}$ \\
N2 $(70 \%)$ & $2.75 \mathrm{~b}$ \\
\hline
\end{tabular}

Nilai dengan huruf yang berbeda menunjukkan perbedaan nyata pada selang kepercayaan $95 \%$

Tabel 5 Hasil uji Duncan pengaruh intensitas naungan terhadap berat basah total bibit $B$. gymnorrhiza

\begin{tabular}{lc}
\hline Intensitas naungan & $\begin{array}{c}\text { Rata-rata berat } \\
\text { basah total }(\mathrm{g})\end{array}$ \\
\hline N0 $(0 \%)$ & $95.96 \mathrm{a}$ \\
N1 $(50 \%)$ & $74.83 \mathrm{~b}$ \\
N2 $(70 \%)$ & $59.67 \mathrm{~b}$ \\
\hline
\end{tabular}

Nilai dengan huruf yang berbeda menunjukkan perbedaan nyata pada selang kepercayaan $95 \%$ 
pertambahan tinggi tanaman. Tinggi tanaman dan jumlah daun merupakan pertumbuhan apikal berupa pertambahan jumlah sel yang menyebabkan pertumbuhan jaringan primer (Iskandar et al. 2015).

\section{Berat Basah Total}

Perlakuan intensitas naungan berpengaruh nyata terhadap berat basah total bibit. Berat basah total merupakan parameter yang digunakan untuk mengetahui kebutuhan air tanaman. Semakin besar berat basah total semai, maka semakin banyak air yang diserap. Berat basah total bibit B. gymnorrhiza lebih besar pada perlakuan tanpa naungan (N0) (95.96 g), dibandingkan degan naungan $50 \%(\mathrm{~N} 1)$ dan naungan $70 \%(\mathrm{~N} 2)$.

Berdasarkan diagram yang disajikan pada Gambar 1, nilai berat basah tertinggi terdapat pada perlakuan A2N0. Selain dipengaruhi oleh naungan, faktor lain seperti unsur hara pada media, tinggi, diameter, ataupun jumlah daun mempengaruhi berat basah bibit.

\section{Berat Kering Total}

Berat kering bibit B. gymnorrhiza tidak menunjukkan hasil analisis yang signifikan terhadap pengaruh naungan, media, maupun interaksi keduanya. Perbedaan berat kering total dapat dilihat pada Gambar

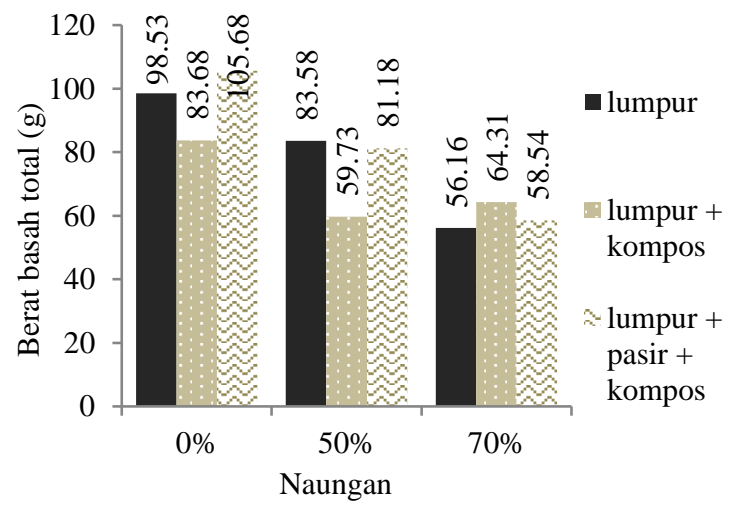

Gambar 1 Diagram berat basah total bibit $B$. Gymnorrhiza

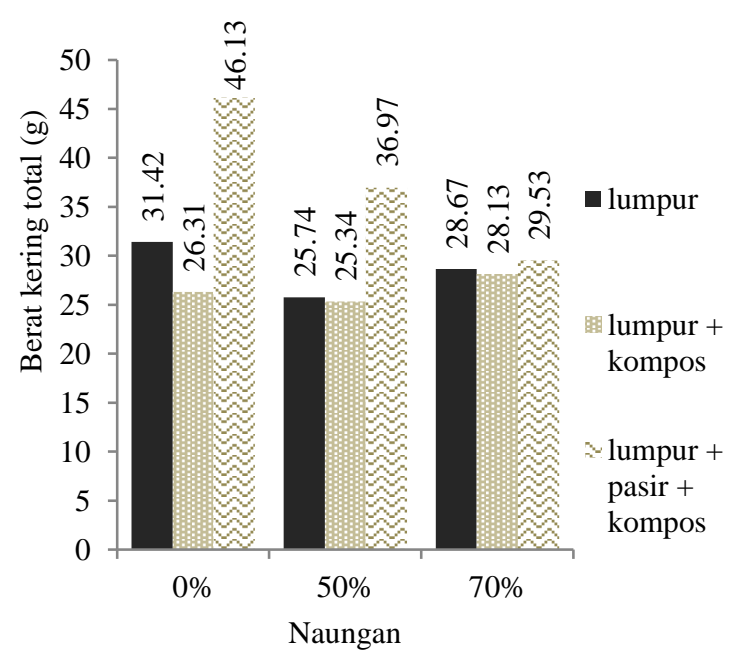

Gambar 2 Diagram berat kering total bibit $B$. gymnorrhiza
2. Diagram diatas menggambarkan bahwa pemberian perlakuan intensitas naungan dan media tanam menghasilkan nilai berat kering total yang tidak jauh berbeda. Berdasarkan data yang disajikan pada Gambar 2, berat kering total bibit B. gymnorrhiza yang paling besar ditunjukkan oleh perlakuan A2N0 (46.13g). Berat kering tanaman yang lebih tinggi menandakan bahwa proses fisiologis tanaman berjalan dengan baik. Hal tersebut mencerminkan akumulasi senyawa organik yang berhasil disintesis oleh tanaman dari senyawa anorganik, terutama air dan karbondioksida (Suryaningrum 2016). Unsur hara yang telah diserap oleh akar mampu memberikan kontribusi terhadap penambahan berat kering dan berat basah tanaman.

Perlakuan A2N0 memberikan hasil berat basah dan berat kering yang paling tinggi. Hal ini disebabkan oleh adanya penambahan kompos dan pasir pada media. Kompos membantu meningkatkan kesuburan tanah sehingga mamicu pertumbuhan pucuk dan perakaran yang baik (Mamonto 2019). Sementara pasir mampu membantu memaksimalkan akar mangrove untuk menyerap nutrisi pada tanah (Tefarani et al. 2019)

\section{Nisbah Pucuk Akar}

Berdasarkan Tabel 6 diketahui bahwa perlakuan intensitas naungan berpengaruh nyata terhadap NPA bibit. Nisbah pucuk akar dihitung dengan membandingan berat kering bagian atas dengan berat kering akar tanaman. Perlakuan tanpa naungan (N0) memberikan hasil yang lebih rendah (3.07), sementara hasil tertinggi diberikan oleh pengaruh naungan 70\% (N2) (5.29). Nilai NPA yang lebih kecil menggambarkan adanya keseimbangan pertumbuhan antara bagian pucuk dengan bagian akar tanaman. Setelah dilakukan pengamatan selama 12 minggu, bibit $B$. gymnorrhiza pada perlakuan naungan terbuka (N0) memiliki pertumbuhan akar dan

Tabel 6 Hasil uji Duncan pengaruh intensitas naungan terhadap nisbah pucuk akar bibit $B$. gymnorrhiza

\begin{tabular}{lc}
\hline \multicolumn{1}{c}{ Intensitas naungan } & $\begin{array}{c}\text { Rata-rata nisbah } \\
\text { pucuk akar }\end{array}$ \\
\hline N0 $(0 \%)$ & $3.07 \mathrm{~b}$ \\
N1 $(50 \%)$ & $3.85 \mathrm{ab}$ \\
N2 (70\%) & $5.29 \mathrm{a}$ \\
\hline
\end{tabular}

Nilai dengan huruf yang berbeda menunjukkan perbedaan nyata pada selang kepercayaan $95 \%$

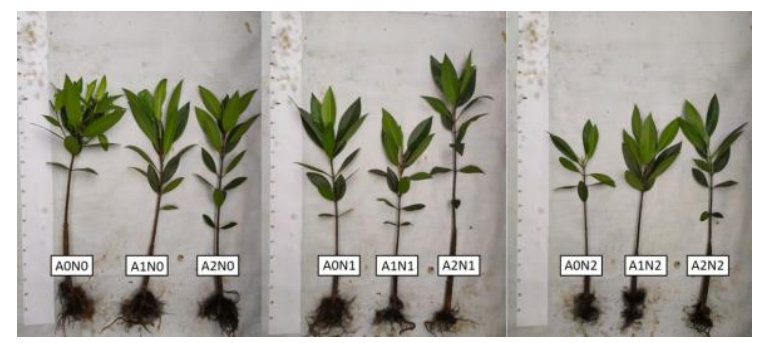

Gambar 3 Keragaman pertumbuhan pucuk dan akar bibit B. gymnorrhiza berumur 6 bulan pada berbagai kombinasi perlakuan media tanam dengan intensitas cahaya 
pucuk yang lebih baik dibandingkan dengan naungan $50 \%$ (N1) dan $70 \%$ (N2) yang disajikan pada Gambar 3. Hal ini sejalan dengan pendapat Lewenussa (2009) bahwa nisbah pucuk akar merupakan perbandingan antara kemampuan tanaman dalam menyerap air dan mineral dengan proses transpirasi dan luasan fotosintesis dari tanaman. Akar yang terbentuk pada tanaman berfungsi untuk menyerap air dan unsur hara dari tanah. Oleh karena itu tersedianya air dan unsur hara dalam jumlah yang cukup, penting untuk pertumbuhan dan perkembangan tanaman (Kusmana et al. 2018).

\section{Media Tumbuh Tanaman}

Lumpur mangrove digunakan sebagai dasar media tanam bibit. Berdasarkan hasil analisis, tanah lumpur tersebut memiliki fraksi pasir $18 \%$, debu $32 \%$, dan klei $50 \%$ dengan kandungan c-organik sebesar $4.58 \%$. Menurut hasil uji segitiga tekstur, jenis tanah ini merupakan jenis tekstur klei atau liat. Hal ini sesuai dengan Marcello (2012) yang menyatakan bahwa jenis mangrove umumnya tumbuh pada lumpur tanah liat yang bercampur dengan bahan organik.

Berdasarkan media yang digunakan pada penelitian, penambahan pasir ditujukan untuk menigkatkan poripori dan aerasi tanah. Penambahan kompos diharapkan dapat meningkatkan kesuburan tanah melalui kandungan hara yang tersimpan sehingga merangsang pertumbuhan tanaman yang sehat. Namun, berdasarkan hasil analisis faktor media tidak memberikan pengaruh signifikan terhadap variabel yang diamati.

\section{SIMPULAN DAN SARAN}

\section{Simpulan}

Perlakuan media dan intensitas naungan memberikan pengaruh yang berbeda terhadap respon pertumbuhan bibit B. gymnorrhiza. Perlakuan intensitas naungan berpengaruh nyata terhadap variabel pertumbuhan tinggi, diameter, jumlah daun, berat basah, dan nisbah pucuk akar bibit. Sementara perlakuan media dan interaksi antara media dengan intensitas naungan tidak berbeda nyata. Berdasarkan hasil penelitian, perlakuan naungan 0\% (N0) dengan media lumpur (A0), media lumpur + kompos (A1), maupun media campuran lumpur + pasir + kompos (A2) memberikan pengaruh paling baik terhadap pertumbuhan bibit B. gymnorrhiza.

\section{Saran}

Saran yang dianjurkan berdasarkan penelitian ini adalah penanaman bibit B. gymnorrhiza berusia 3 bulan pada persemaian sebaiknya dilakukan pada cahaya penuh (naungan 0\%) dengan media tanah berlumpur.

\section{DAFTAR PUSTAKA}

Allen JA, Duke NC. 2006. Bruguiera gymnorrhiza (Large-leafed Mangrove). Species Profiles for
Pacific Island Agroforestry. Hawai'i (US): Permanent Agriculture Resources (PAR).

Duke N, Kathiresan K, Salmo SG, Fernando ES, Peras JR, Sukardjo S, Miyagi T. 2010. Bruguiera gymnorhiza. The IUCN Red List of Threatened Species [internet]. [diunduh 2020 Jan 18] pada: http://dx.doi.org/10.2305/IUCN.UK.20102.RLTS.T178803A7610926.en

Hastuti W, Prihastantai E, Haryanti S, Subagio A. 2016. Pemberian kombinasi pupuk daun gandasil d dengan pupuk nano-silika terhadap pertumbuhan bibit mangrove (Bruguiera gymnorrhiza). Jurnal Biologi 5(2): 38-48.

Iskandar EP, Sampoerno, Saputra SI. 2015. Pertumbuhan beberapa klon bibit kakao (Theobroma cacao L.) pada tanah gambut dan podsolik merah kuning. JOM Faperta 2(1): 1-10.

Jiang Z, Guan W, Xiong Y, Li M, Chen Y, Liao B. Interactive effects of intertidal elevation and light level on early growth of five mangrove species under Sonneratia apetala Buch. hamplantation canopy: turning monocultures to mixed forests. Forest 10(38): 1-13.

Kusmana C, Istomo, Wibowo C, Budi SW, Siregar IZ, Tiryana T, Sukardjo S. 2008. Manual Silvikultur Mangrove di Indonesia. Jakarta (ID): KOICA.

Kusmana C, Hidayat T, Istomo, Rusdiana O. 2018. Growth performance of Bruguiera gymnorrhiza derived from cut-propagule seedling. Biodiversitas 19(1): 208-214.

Lewenussa A. 2009. Pengaruh mikoriza dan bio-organik terhadap pertumbuhan bibit Cananga odorata (Lamk) Hook. Fet \& Thoms [Skripsi]. Bogor: Fakultas Kehutanan, Institut Pertanian Bogor.

Mamonto R, Rombang JA, Lasut MT. 2019. Pengaruh media tanam terhadap pertumbuhan semai Aquilaria malaccensis Lamk. di persemaian. Jurnal Cocos 1(1): 23-36.

Mangora MM, Mtolera MSP, Björk M. 2017. Effects of waterlogging, salinity and light on the productivity of Bruguiera gymnorrhiza and Heritiera littoralis seedlings. African Journal of Marine Science 39(2): 167-174.

Marcello H. 2012. Perubahan mangrove di wilayah pesisir Indramayu [Skripsi]. Depok: Universitas Indonesia.

Permatasari I, Kusmana C. 2011. Respon pertumbuhan semai tancang (Bruguiera gymnorrhiza (L.) Lamk.) terhadap tingkat penggenangan di kawasan mangrove jalan tol Sedyatmo, Jakarta Utara. Jurnal Silvikultur Tropika 2(3): 181-186.

Suci CW, Heddy S. 2018. Pengaruh intensitas cahaya terhadap keragaan tanaman puring (Codiaeum variegetum). Jurnal Produksi Tanaman 6(1): 161169.

Tefarani R. Martuti NKT, Ngabekti S. 2019. Keanekaragaman spesies mangrove dan zonasi di wilayah Kelurahan Mangunharjo Kecamatan Tugu Kota Semarang. Life Science 8(1): 41-53. 